\title{
Imagens da terceira idade: um estudo sobre a representação do idoso veiculada em duas propagandas da televisão brasileira
}

\section{Images of third age: a study about the representation of old persons in two advertisement in brazilian television}

\author{
Márcia Beatriz da Silva ${ }^{1}$
}

\begin{abstract}
Resumo
O presente trabalho se propõe a analisar o discurso em duas propagandas veiculadas pela televisão aberta, sendo uma da década de 1990 e, outra, da década de 2000, nas quais os personagens são pessoas idosas. Tal estudo utilizou as referências da Análise do Discurso de Linha Francesa, que teve como precursor Michel Pechêux. A partir da lingüística procuramos evidenciar as mudanças que ocorreram no enfoque dado às pessoas da Terceira Idade que foram protagonistas dos seguintes comerciais: Copercap Bamerindus, de 1997, e Concurso Banco Real Talentos da Maturidade, de 2007. Além disso, foi possível investigar de que forma o texto publicitário contribui para a mudança da forma de se apresentar o idoso e, também, oferecer subsídios para que se reflita acerca da necessidade de se educar essas pessoas para o consumo consciente. Partindo do pressuposto de que uma propaganda é muito mais do que aparenta ser, conceitos de discurso, ideologia, condições de produção, sujeito discursivo, dentre outros, foram apreendidos e aplicados, na tentativa de compreendê-la em sua abrangência e amplitude. Essa análise permitiu constatar que o idoso, em 1997, era apresentado como frágil e passivo, e, em 2007, como um ser ativo, capaz e com grandes potencialidades, que devem ser mostradas.
\end{abstract}

Palavras-chave: Idoso. Propaganda. Análise do discurso. Televisão

\begin{abstract}
This work has the purpose of analyze speech in two television advertisements has come down to open TV, one of the decade of 1990, and another, of the decade of 2000, in which the characters are old persons. This study used the references of the Analysis of Speech by French Line, which had as precursor Michel Pechêux. From the linguistic evidence seek changes that occurred in the focus given to people of the Third Age that were protagonists of the following commercials: Copercap Bamerindus, 1997, and Real Talent Competition Bank of Maturity, in 2007. Besides, it was possible to investigate how the text advertising contributes to the change in the way to present the elderly and also provide subsidies for which reflects on the need to educate these people for the conscious consumer. Assuming that an advertisement is much more than it appears, concepts of discourse, ideology, conditions of production, discursive subject, among others, were inclued and used in an attempt to understand it in its scope and breadth. This analysis permited to note that the advanced in years, in 1997, was presented as fragile and passive and, in 2007, as a active creature, capable and with great potential, which must be shown. Key-words: Elderly. Advertisement. Analysis of speech. Television.
\end{abstract}

${ }^{1}$ Especialista em Lingüística e Ensino da Língua Materna pela Universidade de Uberaba (Uniube) 
Podemos observar que, ao longo do tempo, a imagem do idoso veiculada nos anúncios publicitários vem se alterando. Por que a imagem, outrora frágil, vem sendo substituída por uma mais saudável e ativa do idoso? Essa é a pergunta que se apresenta para o desenvolvimento do presente trabalho.

Sabe-se que a propaganda, em especial a que é veiculada pela televisão, além de estar sempre presente na vida das pessoas, exerce grande influência nos valores, nas opiniões e no comportamento da sociedade. Consumir produtos e/ou serviços faz parte do nosso cotidiano, é algo natural, inerente ao ser humano, tendo em vista a sociedade capitalista na qual estamos inseridos. E para promover o consumo em um contexto de forte concorrência de mercado, as empresas não podem deixar de investir pesado em propaganda e na publicidade desses produtos.

Segundo Sant'anna (1999), publicidade deriva de "público" e tem sua origem no latim, publicus, que designa aquilo que é público. Para ele, um bom anúncio publicitário é aquele que vende um produto sem chamar a atenção para si e faz com que o interlocutor que não tinha tal necessidade a ser satisfeita, passe a tê-la.

Esse trabalho dos publicitários de dizer as coisas devidamente pensadas, pesquisadas e criadas com a finalidade de parecerem naturais, impossíveis de serem de outro modo (prevendo uma determinada reação do público) contribuem para que se crie a "ilusão" da necessidade de um produto ou serviço. Isso é o "dado-por-certo", questionado por Silverstone (2002, p. 35).

Atualmente, devido a uma série de elementos históricos, a chamada Terceira Idade tem sido alvo de crescente interesse publicitário. Isso não é ocasional. Segundo o último censo do IBGE, a expectativa de vida dos brasileiros, que em 2000 era de 70,4 anos, provavelmente será, em 2050, de 81,3 anos. Ou seja, a probabilidade de um maior número de pessoas idosas tornarem-se consumidoras em potencial é tida como certa. Como a comunicação não pode desprezar esse segmento da população, que está se tornando uma grande fatia do mercado, ela percebe que é preciso saber se dirigir a esse público-alvo.

Para desenvolver este trabalho, é interessante pesquisar o termo Terceira Idade. Segundo Debert (1997), Terceira Idade é uma expressão recente, que se originou na França nos anos 70, que se popularizou com muita rapidez no vocabulário brasileiro e que tem sido utilizada pelos pesquisadores interessados no estudo da velhice não para referir-se a uma idade cronológica precisa, mas a uma forma de tratamento das pessoas de mais idade.

Muitas vezes, velhice é um assunto que é visto como tabu social. Falar sobre o idoso ou sobre seus aspectos torna-se uma tarefa muito delicada e geralmente evitada, tendo em vista não gerar polêmicas e má interpretação.

Atualmente, percebe-se que a palavra "velha" está carregada de sentidos pejorativos. Geralmente, é usada para referir-se ao que já não serve mais, ao que precisa ser substituído pelo novo e que pode ser descartado. E isso contribui para que se estabeleça ou se destaque ainda mais o preconceito, afinal, em nenhuma outra faixa etária a questão da idade é tão evidenciada.

Debert (1997) faz alusão ao fato de a terceira idade não ser sinônimo de decadência, pobreza e doença, e sim, de um tempo privilegiado para atividades livres dos constrangimentos do mundo profissional e familiar.

Atualmente, já se percebe uma mudança nos enfoques sobre o idoso: há um discurso empenhado em rever os estereótipos negativos da velhice. No meio publicitário, hoje, há um outro termo bastante utilizado para se referir a essa faixa etária: "Melhor Idade". Provavelmente foi criado para fazer referência ao fato de essa fase da vida poder ser considerada a melhor devido à maturidade que já se conseguiu alcançar e às experiências adquiridas que possibilitam vivenciar com mais intensidade 
o momento que se vive. As novas imagens do envelhecimento ocupam um espaço cada vez maior na mídia e abrem mais espaço para a criação de novos mercados de consumo. Desse modo, pareceme interessante investigar qual é a contribuição do texto publicitário para a mudança da forma de se apresentar o idoso.

Como vimos anteriormente, o crescente aumento da população idosa é fato. Estamos presenciando o surgimento de um fenômeno social, com reflexos políticos, econômicos e culturais de grande dimensão. Da mesma forma, tem sido crescente a inserção de idosos em comerciais. Basta folhear jornais e revistas, ouvir rádio ou assistir à televisão para comprovar isso.

Ao fazer tal inserção, a mídia procura atingir essa parcela de consumidores, que descobriram ser significativa; afinal, têm poder aquisitivo e estão em ascenção no mercado de consumo. Isso pode ser percebido em chamadas como: "Você que é aposentado ou pensionista do INSS, pode fazer um empréstimo de até três vezes o valor do seu benefício".

\section{Segundo Debert (1997):}

[...] o fato de os mais velhos constituírem o grupo que, em todas as classes sociais, tende a ter maior disponibilidade para o consumo, dá novo significado à experiência de envelhecimento. O idoso transformase em um novo ator que não está mais ausente dos discursos, $[\ldots]$ é um ator que também está presente na definição de novos mercados de consumo e formas de lazer.

Percebe-se que, a cada dia, há mais pessoas idosas não só em comerciais, mas também no trabalho e em vários outros campos da sociedade. Analisar de que forma o idoso era apresentado numa propaganda de 1997, de que forma passou a ser enfocado dez anos depois (tendo como base um comercial veiculado pela televisão em 2007) e o porquê dessa mudança, é o desafio deste trabalho.

Além disso, faz-se necessário refletir sobre os discursos a respeito da velhice que circulam na mídia nacional, mesmo que seja apenas de um recorte, tendo em vista aprofundar o conhecimento acerca da imagem dos idosos que passou a ser veiculada e as conseqüências disso para eles. Essa discussão é particularmente importante para os produtores de Comunicação Social, pois, como argumenta Fonseca (2005):

\begin{abstract}
Nossa imagem de mundo jamais é uma cópia da realidade, pois nossos propósitos direcionam nossa inteligência e encaminham o raciocínio procurando encaixá-lo a fins moldados a partir de decisões anteriores fundamentadas na livre escolha pessoal - ou seja, a partir de definições éticas e políticas. Enquanto sujeitos recriadores de sua própria cultura, produtores (e não meros reprodutores) de sua própria sociedade, não cabe aos homens e às mulheres refletir a realidade, mas refletir sobre ela, participando de sua permanente reelaboração, contribuindo na cotidiana reconstrução da verdade que, por ser humana, é um projeto inacabado e em constante reintepretação.
\end{abstract}

Num período de dez anos muitas mudanças ocorrem. Analisar de que forma a mídia atua na construção da imagem das pessoas idosas em peças publicitárias, como se aborda a questão da terceira idade e qual imagem de idoso o marketing comercial constrói e apresenta nesse gênero textual são fundamentais para que se encontre a resposta para a pergunta apresentada no início deste trabalho.

Com base nessa questão será feita uma análise mais aprofundada, utilizando as referências da Análise do Discurso de Linha Francesa (preconizada por Michel Pêcheux) e considerando dois comerciais veiculados pela mídia televisiva: um, de 1997 e outro, de 2007, nos quais o idoso é o personagem principal.

Mostrar como a publicidade lança mão da figura do idoso, quais efeitos de sentido são gerados a partir dessa utilização e provocar reflexões acerca disso são os principais objetivos deste trabalho.

Com isso, será possível oferecer subsídios para que se reflita acerca da necessidade de educar o idoso para o consumo consciente.

\section{Análise do Discurso}

Segundo Fernandes (2007), a Análise do Discurso (AD) é um espaço teórico transdisciplinar que oferece teorias e métodos para a reflexão sobre a produção e a circulação dos sentidos sociais. 
Como o próprio nome diz, a AD trata do discurso. De acordo com o senso comum, essa palavra é usada para se referir a pronunciamentos políticos ou a frases proferidas de maneira eloqüente. Para Orlandi (2007, p. 15), etimologicamente, a palavra "discurso" tem em si a idéia de curso, de percurso, de correr por, de movimento.

Para a $\mathrm{AD}$, discurso é muito mais que isso. Considerando-se o aspecto discursivo da comunicação, ela afirma que todo enunciado constitui-se em um discurso que é produzido em um determinado contexto sócio-histórico-políticoeconômico.

Segundo Fernandes (2007, p.9), discurso "é um objeto do qual se ocupa uma disciplina específica, é um objeto de investigação científica." Para Orlandi (2007, p.16), “é o lugar em que se pode observar a relação entre língua e ideologia, compreendendo-se como a língua produz sentidos por/para os sujeitos." De acordo com Santos e Fernandes (2006, p. 208), "é uma interação social, decorrente de uma prática sócio-cognitiva e ligada a convenções sociais."

A partir das definições apresentadas, percebese que o discurso, para a $\mathrm{AD}$, vai além da fala, da língua e do texto. Não se restringe apenas a esses elementos, embora necessite desses elementos lingüísticos para ter uma existência material. Fernandes (2007, p. 18) afirma:

[...] discurso não é a língua, nem o texto, nem a fala, mas que necessita de elementos lingüísticos para ter uma existência material. [...] implica uma exterioridade à língua, encontra-se no social e envolve questões de natureza não estritamente lingüística. Referimo-nos a aspectos sociais e ideológicos impregnados nas palavras quando elas são pronunciadas.

Para se analisar o discurso, segundo a AD, é necessário analisar aspectos sociais, ideológicos, históricos que estão impregnados nas palavras que estão sendo pronunciadas. Há todo um contexto que precisa ser considerado, bem como os sujeitos, a posição que ocupam e a ideologia. É preciso romper com as estruturas lingüísticas para se chegar ao discurso.
Pode-se afirmar que, devido à complexidade, para se analisar o discurso, segundo a $\mathrm{AD}$, é necessário compreender também os conceitos de "enunciado", "ideologia", "sujeito discursivo", "condições de produção" e "sentido".

Enunciado se distingue de frase, de proposição, de ato de fala. Está inserido num discurso e existe em decorrência da função enunciativa. Implica uma relação que envolve os sujeitos, a história e a materialidade lingüística e depende do lugar sóciohistórico-ideológico em que estão os sujeitos que o enunciam.

Quando são empregadas determinadas palavras, expressões, frases, por exemplo, isso que se enuncia vai além dos significados delas, que estão nos dicionários. Os sentidos que são produzidos decorrem da ideologia dos sujeitos que as enunciam e da forma como compreendem a realidade política e social na qual estão inseridos.

Se a enunciação está ligada à ideologia, o que vem a ser ideologia? Segundo Fernandes (2007, p. 29), "é uma concepção de mundo de um determinado grupo social em sua circunstância histórica. É inerente ao signo em geral." Sendo assim, diante de toda e qualquer palavra que é enunciada, é possível verificar qual (ou quais) ideologia (s) a integra (m). Ou seja, o enunciado revela a ideologia do sujeito discursivo.

Para Orlandi (2007, p. 48), a ideologia aparece como "efeito da relação necessária do sujeito com a língua e com a história para que haja sentido." Por sua vez, o sujeito discursivo é constituído na interação social. "Em sua voz, um conjunto de outras vozes heterogêneas se manifestam." (FERNANDES, 2007, p. 29). Ou seja, ele é polifônico e é constituído por uma heterogeneidade de discursos.

Falar em polifonia significa referir-se às várias vozes que provêm de diferentes espaços sociais e de diferentes discursos, que são constitutivas do sujeito discursivo. A presença dessas diferentes vozes constitutivas do sujeito, implícita ou explicitamente, caracteriza uma heterogeneidade discursiva. 
Vale ressaltar que, para a $\mathrm{AD}$, o sujeito não é compreendido como um ser individualizado ou como uma pessoa, e sim como um ser social e ideológico, em um dado momento da história e não em outro. Ao se expressar, expressa um conjunto de outras vozes de uma determinada realidade social.

Se o enunciado é proferido por um sujeito discursivo, há que se considerar em que condições de produção isso se deu. O que vem a ser essas condições? "São aspectos históricos, sociais e ideológicos que envolvem o discurso e que possibilitam que ele seja produzido." (FERNANDES, 2007, p. 29). Ou seja, o contexto imediato e o contexto sócio-histórico-ideológico têm influência direta na produção do enunciado. O enunciado, portanto, é singular. Se for dito, por exemplo, num outro momento histórico e social, já será um outro enunciado. As condições de produção “implicam o que é material (a língua sujeita a equívoco e a historicidade), o que é institucional (a formação social, em sua ordem) e o mecanismo imaginário." (ORLANDI, 2007, p. 40).

Embora tais definições estejam dispostas uma a uma, sabe-se que tais conceitos estão intimamente ligados e inter-relacionados ao se fazer a análise do discurso.

O instrumental teórico da Análise do Discurso (AD) permite que seja feita uma investigação dos efeitos de sentido presentes na superfície discursiva das propagandas analisadas. Com base no instrumental teórico da $\mathrm{AD}$, analisaremos as posições do sujeito-alvo nos dois anúncios publicitários em questão, bem como os efeitos de sentido que esse discurso provoca.

\section{Representação de Idosos nas Propagandas}

Tomando como base a análise do discurso será possível perceber como o idoso era apresentado em propagandas dez anos atrás e como isso é feito atualmente.
Para efetivar a análise, foram selecionados dois comerciais veiculados pela televisão aberta: um, de 1997, e outro, de 2007.

$\mathrm{O}$ primeiro anúncio publicitário escolhido foi veiculado pela televisão aberta, em rede nacional, em 1997. O produto anunciado é o título de capitalização do Banco Bamerindus, denominado Copercap. Os personagens, um senhor idoso e uma senhora idosa, passando a idéia de serem marido e mulher, têm como cenário a sala de uma casa, provavelmente a desse suposto casal.

O videotape (VT) tem início com a senhora idosa entrando nessa sala, segurando um pacote na mão, embrulhado em papel de presente. O senhor idoso, fazendo o papel de marido da senhora idosa, está sentado num sofá.

A senhora entra e diz: Adolfo, comprei o nosso aparelho de som. Ele pergunta: Hein??? Ela responde: Som. E soletra: vi-tro-la. Ele pergunta, novamente, demonstrando que não ouviu o que ela disse: Hein???? E ela diz: Aquele que a gente tava juntando dinheiro desde o nosso casamento. Comprei! E ele repete: Hein????

O diálogo entre eles termina por aí e tem início a seguinte locução em off: Está demorando juntar dinheiro para realizar seu sonho? Faça um Copercap Bamerindus. Você pode ter na mão o dinheiro pra comprar o que quiser, já na semana que vem. No final, o VT é assinado com o logotipo do Banco Bamerindus.

O segundo anúncio selecionado também foi veiculado pela televisão aberta, em rede nacional, em 2007 e apresentava o concurso "Talentos da Maturidade", promovido pelo Banco Real ABN AMRO.

Os personagens principais, quatro pessoas de terceira idade, sendo dois homens e duas mulheres (além de outros três figurantes) são mostrados em dois ambientes diferentes e de aparente tranqüilidade: cômodos de uma casa antiga e uma praça pública. 
O VT tem início com uma versão da música "Menina Faceira", de Chiquinha Gonzaga. Enquanto a música é tocada, detalhes do cenário são mostrados: um rádio de modelo muito antigo, uma cadeira de balanço e cortinas transparentes sendo balançadas pelo vento. Assim que isso é mostrado, a música passa a ser fundo musical (background) e um locutor em off pergunta: Você é do tempo que sessenta anos era hora de parar? Que tal ... se reinventar?

Enquanto isso é dito e a música continua em background, é mostrado um outro cenário: uma praça pública. A câmera faz uma panorâmica na praça e pode-se ver uma mesa de alvenaria, na qual está pintado um tabuleiro de damas.

Abaixa-se novamente o volume da música e o locutor em off diz: Ter mais de sessenta anos nos dias de hoje significa poder sonhar, criar e se reinventar.

A música volta com o volume mais alto, enquanto vão sendo mostrados mais outros personagens idosos: uma senhora assentada numa cadeira, na varanda, escrevendo algo num caderno, e sorrindo; uma outra senhora digitando algo num computador, de forma concentrada e feliz; um senhor idoso assentado num banco de madeira e fazendo um trabalho artesanal, numa tela, também bastante sorridente; e um outro senhor tocando violão e cantando.

Enquanto esses personagens são apresentados, aparecem nomes de pessoas com mais de sessenta anos, com suas respectivas idades e profissões. $\mathrm{O}$ locutor em off diz: Concurso Banco Real Talentos da Maturidade. Participe! É hora de reinventar. Vem com a gente!

Em seguida, o personagem que estava tocando violão aparece cantando, assentado no banco da mesma praça que foi mostrada no início da propaganda, com mais outros quatro senhores (de meia-idade e de terceira idade) cantando uma música e tocando vários instrumentos, como cavaquinho e pandeiro; porém não dá para perceber se é a mesma música que está sendo usada como background.

$\mathrm{Na}$ tela, sobre um fundo preto, aparecem os caracteres: Inscrições até 17 de agosto de 2007, e o número de telefone 0800120077 . No final, o VT é assinado com o logotipo do banco e mais os seguintes caracteres: Fazendo mais que o possivel. E, logo abaixo: Banco Real - ABN AMRO e o seguinte endereço eletrônico: www.bancoreal.com. br/talentos

A análise que se faz apóia-se tanto na linguagem verbal quanto na não-verbal, pois é o conjunto vídeo / áudio (imagem, locução, trilhas, efeitos) que tem a função de mostrar, interagir e persuadir o receptor; afinal, televisão se faz com os sentidos visão e audição.

Palavras, expressões, marcas lingüísticas e da oralidade contidas nos comerciais analisados são sinalizadores de grande importância para a percepção do discurso que subjaz a esses dois textos publicitários.

Segundo Ribeiro (2007, p. 3):

\begin{abstract}
É possível inferir que os sentidos produzidos sobre determinados fenômenos sociais como, por exemplo, aqueles atribuídos à velhice, decorrem de um contexto imediato e de um conjunto de possibilidades de enunciação anteriores, tanto em meios de comunicação de massa, como em conversas do dia-a-dia.
\end{abstract}

As duas propagandas selecionadas têm, em comum, bancos como anunciantes: Banco Bamerindus e Banco Real. Ambas têm como personagens principais pessoas da terceira idade, embora apresentadas de forma diferente: ora como frágeis, ora como pessoas ativas, e foram veiculadas em rede de televisão aberta. Esse fato é significativo, tendo em vista a quantidade de pessoas que se consegue atingir num mesmo tempo (mais do que se fossem veiculadas em TV fechada).

Também apresentam produções de boa qualidade e bom tratamento das imagens, pois foram produzidas por agências especializadas. Isso é indicador de visão de mercado, por parte 
dos anunciantes, que percebem a importância e a necessidade de se investir em publicidade, a fim de se obter retorno financeiro e o reconhecimento do público.

No primeiro comercial, o Banco Bamerindus oferece como produto um título de capitalização, denominado Copercap. Com base nisso, já se pode perceber que não está dirigido a todos os públicos, apenas aos de classe média e de classe média alta, haja vista que, de maneira geral, os mais pobres não têm condições financeiras para adquirir tal produto.

Os dois personagens são idosos já de idade avançada, aparentemente com mais de 75 anos. Isso pode ser percebido pelos cabelos totalmente brancos, pele bastante enrugada, dificuldade de locomoção e, também, pelo fato de o senhor idoso representar uma pessoa surda. Passa-se a idéia de que ambos moram na mesma casa, sozinhos. A senhora é apresentada como mais lúcida, mais ativa e mais jovem que o senhor, considerando que nesse contexto é ela quem sai e compra o aparelho de som que desejavam desde que se casaram.

O fato de se mostrar que eles demoraram muito para conseguir realizar um sonho de quando ainda eram jovens, também está carregado de sentido: demorou tanto que até deu tempo de envelhecer.

Embora o comercial, inicialmente, nos passe a idéia de que é destinado às pessoas da terceira idade, ao se fazer uma análise mais aprofundada, percebese que isso não é verdade. Ele é dirigido às pessoas mais jovens, sugerindo que elas se antecipem e realizem seus sonhos, através do não-dito. Ou seja, é como se dissessem: você que é jovem, tem sonhos e pretende realizá-los com certa rapidez, adquira já o título de capitalização Copercap, do Banco Bamerindus, e evite ter que esperar tanto tempo para concretizá-los.

Segundo Orlandi (2007), sempre há a possibilidade de outros sentidos, pois não existe um único, absoluto, definitivo. Há uma carga de significados diversos porque o dizer tem história.
Ao longo daquilo que é dito (do dizer) e do que tem sentido, há também os não-ditos que têm significado, levando em consideração apenas o que é relevante para uma situação significativa (não é qualquer não-dito que pode ser considerado).

Orlandi (2007, p. 82) afirma: "Se as novas maneiras de ler, inauguradas pelo dispositivo teórico da análise do discurso, nos indicam que o dizer tem relação com o não dizer, isto deve ser acolhido metodologicamente e praticado na análise.”

Nesse comercial, a imagem de idoso é a de alguém frágil, passivo, paciente, acomodado, que fica aguardando até que seja possível. Isso pode ser percebido no contexto de produção, quando ambos demonstram que foram capazes de esperar muito tempo para concretizar um sonho e que não buscaram outros meios para tal.

Há que se ressaltar o uso da imagem dos dois velhinhos como pessoas pouco espertas, alienadas e que demoraram muito para realizar um sonho que já poderia ter sido realizado há muito tempo e com certa facilidade.

O cenário montado, de uma possível sala da casa do casal, nos permite inferir que ambos têm uma vida simples, porém confortável. Os móveis retratam um determinado período histórico, em que a ausência da informática nesse tipo de residência ainda era comum (computador ainda era para poucos), os aparelhos eletrônicos não eram tão sofisticados, mas denotavam um certo conforto para um casal da terceira idade, em 1997.

O ambiente é calmo, não tem a presença de barulho de automóveis e de outros sons como música alta e nem pessoas conversando. $\mathrm{O}$ fato de a senhora idosa chegar (possivelmente da rua) após ter feito compras, e de o marido estar sentado num sofá à espera dela, é um sinalizador a se considerar: já estava em curso uma "inversão" de papéis, em que a mulher ocupava uma posição mais ativa na sociedade, ao invés de ser apenas uma dona de casa à espera do marido. 
O senhor, supostamente o marido da velhinha, é mostrado como uma pessoa não muito saudável. Além de franzino, porta-se como uma pessoa com alto grau de surdez. Isso pode ser percebido na quantidade de vezes que ele repete a interjeição "HEIN", simulando que não está ouvindo o que a senhora está dizendo. Inclusive, o diálogo deles se encerra com essa mesma interjeição, ou seja, ele é mesmo surdo, pois, nem a velhinha gritando e soletrando a palavra "vitrola", ele consegue ouvi-la.

Nesse comercial não há interrupções na cena para que sejam feitas inserções da voz do narrador em off. Ele aparece apenas após o diálogo dos dois personagens, no final da propaganda, para apresentar o produto "Copercap Bamerindus". Tem uma voz firme (e até sarcástica, haja vista que no VT utilizou-se o apelo humorístico), faz uma pergunta bem específica: Está demorando juntar dinheiro para realizar seu sonho? e, logo em seguida, já apresenta a solução, a resposta para a pergunta, que, segundo ele, é a aquisição do produto ofertado pelo banco: Faça um Copercap Bamerindus. Vale ressaltar a utilização de verbo no imperativo (Faça), que expressa ordem, comando e induz a uma ação. Além disso, ainda enfatiza a rapidez com que se consegue tudo isso, através da expressão já na semana que vem. Também apresenta esse produto do banco como um facilitador não só para a realização de um sonho, mas como uma forma mágica para se adquirir qualquer produto, quando diz: ... pra comprar o que quiser.

Os dizeres explicitam segurança, confiabilidade e têm elementos persuasivos. Conduzem o telespectador a repensar as formas de se conseguir juntar dinheiro para comprar algo que é objeto de um sonho. Também induzem as pessoas idosas a pensarem que perderam muito tempo, que já estão na fase final da vida e que não podem mais esperar para realizar os outros sonhos que ainda têm. E, conseqüentemente, precisam adquirir o produto que está sendo anunciado.

No segundo comercial, o Banco Real lança um concurso denominado "Talentos da Maturidade". Com base nisso, já se pode perceber uma outra visão que se tem do idoso. Primeiramente, porque usa o termo "maturidade", em vez de "velho" ou "idoso" (que já são usados pejorativamente) e, segundo, porque atribui às pessoas com mais de sessenta anos a capacidade de serem talentosas, de terem algo de bom para ser mostrado.

Como se pode perceber, essa é uma forma diferente de se referir ao idoso, se comparada ao outro comercial analisado anteriormente. Essa é uma comprovação de como a análise do discurso concebe o sujeito como um ser social e ideológico, em um determinado momento da história, e não em outro.

Os personagens são pessoas idosas, porém não de idade tão avançada. Aparentam ter entre 60 e 65 anos e demonstram ser ativos e com vitalidade, pois escrevem, digitam em computador, fazem trabalhos artesanais, tocam violão e cantam. Essa posição ativa dos idosos é usada como reforço à idéia que o banco quer passar e também do nome do concurso que eles realizam: Talentos da Maturidade. Segundo Ribeiro (2007), o nome do concurso alia a presença institucional (Banco Real) tanto à criatividade (Talentos) quanto ao público idoso (Maturidade). Além disso, enfatiza o dado de que as pessoas mais velhas têm talentos e que esses podem e devem ser mostrados. É uma forma de comprovação da mensagem e do discurso que estão sendo veiculados.

Outro aspecto a ser evidenciado é em relação à fisionomia dos personagens. Todos demonstram estar felizes com o que estão produzindo. Isso é percebido no sorriso, no semblante alegre, na concentração com que desempenham suas atividades. Ou seja, nada de apresentar o idoso como um sujeito passivo, sentado numa cadeira de balanço vendo a vida passar. Tal idéia é reforçada quando o locutor em off diz: Ter mais de sessenta anos nos dias de hoje significa poder sonhar, criar e se reinventar. É a força do discurso para persuadir as pessoas com mais de sessenta anos que elas têm 
o poder nas mãos, que podem ter sonhos e objetivos independentemente da idade, que são capazes de criar e de dar novos significados à vida.

Em outra fala do narrador em off Você é do tempo que sessenta anos era hora de parar?, pode-se perceber que é passada a mensagem de que pensar em parar aos sessenta anos é coisa do passado, do tempo antigo e que só os que são dessa época é que pensam assim; que os tempos mudaram e que as pessoas com mais de sessenta anos, de hoje, já pensam diferente. Por isso a utilização do verbo "ser", no pretérito perfeito: ERA. Chama essas pessoas para serem modernas, "antenadas", e pensarem e agirem de forma diferente dos velhos de dez anos atrás quando tinham a mesma idade deles.

Em seguida, ao sugerir Que tal se reinventar?, coloca para o idoso que ele pode transformar-se, descobrir-se, evoluir, ser moderno (deixar de pensar como antigamente), que é capaz de mudar uma situação e que pode ver e viver essa fase de uma forma diferente. Ou seja, pode e deve reinventar a própria vida, seus objetivos e seus sonhos. O uso da partícula "se" também nos remete à idéia de que o Banco Real quer passar a imagem de que é um banco preocupado com o idoso, que sugere que ele faça algo por ele mesmo, e não pelos outros; que ele pode viver intensamente, mesmo já tendo sessenta anos ou mais. E tudo isso é bem diferente de cerca de dez anos atrás, quando passava-se a idéia de que aos sessenta anos tudo o que tinha que ser feito já deveria estar "pronto" e que, se não o tivesse, não dava mais tempo.

A nova forma de ver a fase dos sessenta anos pode ser comprovada também no uso da palavra "hoje" na frase: Ter mais de sessenta anos nos dias de hoje significa poder sonhar, criar e se reinventar. [grifo nosso] Ainda nessa frase há a utilização do vocábulo "poder", que contribui para que essas pessoas sintam que são capazes, que podem ter sonhos, objetivos de vida e que ainda têm o poder nas mãos para fazer algo, que podem ser ativas e que têm talento para tal.
O referido banco coloca-se na posição de parceiro do idoso nessa ação. Isso é mostrado quando aparecem os dizeres Concurso Banco Real e Vem com a gente. Passa-se a idéia de que há uma parceria entre a referida instituição bancária e as pessoas que têm sessenta anos. Essa sintonia pode ser percebida também quando o banco coloca à disposição dessas pessoas um telefone, para o qual elas podem ligar gratuitamente, o que provocará uma maior aproximação anunciante / público-alvo através dos diálogos que serão estabelecidos, da troca de idéias e de informações, da efetivação da adesão dos idosos ao concurso, sem que seja preciso pagar nada no estabelecimento desse contato mais direto. Subentende-se que o banco respeita a aposentadoria que o idoso recebe, deixando que ele a gaste investindo em suas atividades e nos seus talentos. É óbvio que, depois, após conquistar a simpatia, a confiança e o respeito do possível cliente, atrairá esse idoso e oferecerá a ele outros produtos bancários, tais como empréstimos, mas, nesse momento, isso não é mostrado. É um "trabalho" de conquista e de provável fidelização.

Além disso, o banco se coloca como um parceiro, um "amigo do peito", que faz muito mais, que vai além das suas possibilidades para ficar ao lado dos idosos nessa fase da vida, em: Banco Real. Fazendo mais que o possível. As interrupções nas cenas para inserção da voz do locutor em off também reforçam a parceria do banco com o idoso.

A utilização de vários espaços como cenário, objetos de cena e atuação com semblantes felizes contribuem para passar a imagem de um ser humano ativo e inserido em contextos atuais. Enfatiza a idéia de que há atividades prazerosas tais como música, literatura, artes plásticas e informática que podem ser desenvolvidas, descobertas e até resgatadas por tais pessoas e que isso é sinônimo de vitalidade.

Os dizeres explicitam confiabilidade, parceria, simpatia e empatia e conduzem o telespectador a acreditar na instituição e a percebê-la como aquela que se preocupa, de fato, com as pessoas mais 
velhas e que possibilita a elas fazer desabrochar o potencial que estava adormecido (seja por não ter sido descoberto ou por não ter tido tempo enquanto trabalhava e sustentava a família) e uma melhor qualidade de vida nessa etapa.

\section{Considerações Finais}

Tomando por base a análise feita, percebese que, atualmente, o idoso passou a ser visto como um forte consumidor em potencial e que, por isso, a propaganda tem se voltado para esse público apresentando produtos e serviços que estão dirigidos a ele. Nota-se que houve uma mudança nesse aspecto quando se vê que, na primeira propaganda analisada, do Banco Bamerindus, o idoso era apenas um personagem de divulgação de um produto não direcionado às pessoas da terceira idade (e sim a pessoas de outra faixa etária), enquanto que, no segundo comercial, os personagens divulgam algo que é específico para as pessoas idosas.

Percebe-se também, na propaganda do Banco Real, um esforço em apresentar a velhice como uma fase da vida em que é possível obter novas conquistas, buscar o prazer e a satisfação pessoal. Isso é feito quando se incentiva os idosos a darem continuidade à vida social através da realização de atividades artísticas e quando se mostra que eles podem ser valorizados como indivíduos e aproveitar essa etapa de forma intensa e prazerosa. Destina-se aos idosos que já são artistas, aos que desejam ser e aos que podem descobrir seus talentos participando do concurso que está sendo lançado.

Diferentemente do que é mostrado no primeiro comercial, em que se usou a imagem dos dois velhinhos como pessoas tolas, pouco espertas e "fora de órbita", no segundo, nota-se que foi passada a imagem do idoso como uma pessoa culta, ativa, inserida em atividades artístico-culturais e fazendo parte do mundo moderno.
Há que se ressaltar também o fato de, em ambos comerciais, terem sido utilizadas imagens de idosos que são pessoas comuns. Com isso, conseguese uma maior identificação do público com esses personagens, o que possibilita uma maior aproximação dos telespectadores às empresas anunciantes e, conseqüentemente, adesão ao apelo que elas fazem.

Em síntese, percebe-se que há mudanças significativas na forma de apresentar o idoso nos dois anúncios analisados. Cada vez mais são ressaltadas qualidades como autonomia, independência, mobilidade, busca pelo prazer, sociabilidade, satisfação pessoal e criatividade, atreladas à figura do idoso.

Embora a forma de referir-se ao idoso tenha sido diferente nos dois anúncios publicitários, não se pode deixar de considerar o que está por trás de tudo o que é dito. Seja de uma forma pejorativa ou de outra mais eloqüente, o discurso está centrado na venda de um produto ou de um serviço, afinal, esse é o grande objetivo desse gênero denominado propaganda. É uma nova forma de abordar a imagem das pessoas idosas adotada pela publicidade.

\section{Referências}

DEBERT, Guita Grin. A invenção da terceira idade e a rearticulação de formas de consumo e demandas políticas. 1997. Disponível em: $<$ http:// www.anpocs.org.br/portal/publicacoes/rbcs_00_34/ rbcs34_03.htm>. Acesso em: 15 mar. 2011.

FERNANDES, Cleudemar Alves. Análise do discurso: reflexões introdutórias. 2. ed. São Carlos: Claraluz, 2007.

FONSECA, André Azevedo da. Jornalismo para a transformação: a pedagogia de Paulo Freire aplicada às Diretrizes Curriculares de Comunicação Social. In: CONGRESSO BRASILEIRO DE CIÊNCIAS DA COMUNICAÇÃO, 28., 2005, Rio de Janeiro. Anais... São Paulo: Intercom, 2005. Disponível em: <http://www.intercom.org. br/papers/nacionais/2005/resumos/R0561-1.pdf>. Acesso em: 20 fev. 2011. 
ORLANDI, Eni Puccinelli. Análise do discurso: princípios e procedimentos. 7. ed. Campinas: Pontes, 2007.

RIBEIRO, Raquel Noel. A construção da velhice positivada em propagandas televisivas direcionadas ao público idoso. 2007. Dissertação (Mestrado em Psicologia Social) - Pontifícia Universidade Católica de São Paulo - PUCSP, São Paulo, 2007.

SANT'ANNA, Armando. Propaganda: teoria: técnica: prática. 7. ed. São Paulo: Pioneira, 1999.

SANTOS, João Bosco Cabral dos Santos; FERNANDES, Cleudemar Alves. (Org.). Análise do discurso: objetos literários e midiáticos. Goiânia: Trilhas Urbanas, 2006.

SILVERSTONE, Roger. Por que estudar a mídia. São Paulo: Loyola, 2002. 
